\section{Bereich, grenzwertiger}

G. Schumann

Hannover, Deutschland

Englischer Begriff borderline range; grey zone

Definition Bereich der Werte einer Messgröße, der zwischen dem Referenz- und dem pathologischen Bereich liegt, in dem keine Bewertung „gesund“ oder „krank“ erfolgt.
Beschreibung Die Verteilung der Messergebnisse einer gesunden Population überlappt sich bei den meisten biologischen Messgrößen mit der von kranken Populationen. In dem Überlappungsbereich besteht eine Zuordnungsunsicherheit, die an dem Punkt am höchsten ist, an dem sich die Verteilungskurven kreuzen.

\section{Literatur}

Qualitätsmanagement in der Laboratoriumsmedizin (2001) Teil 2: Begriffe zur Qualität und Anwendung von Untersuchungsverfahren. Beuth-Verlag, Berlin. DIN 58936-2:2001, 6.4 